\title{
PENERAPAN PEMBELAJARAN KOOPERATIF TIPE STUDENT TEAMS ACHIEVEMENT DIVISION (STAD) TERHADAP HASIL BELAJAR PAI DI SEKOLAH DASAR
}

\author{
Haerudin \\ PGSD FKIP UBP Karawang \\ haerudin@ubpkarawang.ac.id
}

\begin{abstract}
This study aims to examine how much the effectiveness of the application of cooperative learning techniques learning Student Teams Achievement Division (STAD) on learning outcomes. This research was conducted with research subjects fifth grade students of SD Negeri Kertamulya II. The method used is a method of a class action (PTK), which consists of two cycles, each cycle consisting of two meetings. The collection of data through a pretest and posttes, observation, field notes, and interviews. The results obtained from this study is that the implementation of cooperative learning model type Student Teams Achievement Division (STAD) can significantly improve student learning outcomes. It can be seen from the results posstest increased compared to pretest and also the achievement of all students in a large part of the value above the maximum completeness criteria (KKM).
\end{abstract}

Keywords: Model Student Teams Achievement Division (STAD), Results Learning, Action Research.

\begin{abstract}
Abstrak: Penelitian ini bertujuan untuk menelaah seberapa besar efektifitas penerapan pembelajaran teknik cooperative learning Student Teams Achievement Division (STAD) terhadap hasil belajar. Penelitian ini dilakukan dengan subyek penelitian siswa kelas V SD Negeri Kertamulya II. Metode penelitian yang digunakan adalah metode tindakan kelas (PTK) yang terdiri dari 2 siklus, setiap siklus terdiri dari 2 pertemuan. Pengumpulan data melalui pretest dan posttes, observasi, catatan lapangan, dan wawancara. Hasil yang diperoleh dari penelitian ini adalah bahwa penerapan model pembelajaran kooperatif Tipe Student Teams Achievement Division (STAD) secara signifikan dapat meningkatkan hasil belajar siswa. Hal ini dapat dilihat dari hasil posstest yang meningkat dibandingkan pretest dan juga tercapainya nilai seluruh siswa sebagaian besar diatas Kriteria Ketuntasan Maksimal (KKM).
\end{abstract} Kata Kunci: Model Student Teams Achievement Division (STAD), Hasil
Belajar, Penelitian Tindakan Kelas (PTK). 


\section{PENDAHULUAN}

Pendidikan memegang peranan penting di dalam kehidupan setiap pribadi manusia, karena pendidikan adalah kegiatan yang dilakukan dalam rangka mengembangkan potensi yang dimiliki peserta didik dengan harapan supaya menjadi manusia yang beriman, berilmu, dan berakhlak mulia. Hal ini sesuai dengan tujuan pendidikan nasional yang tercantum dalam pasal 3 ayat 1 Undang -undang Nomor 20 tahun 2003 tentang Sistem Pendidikan Nasional yaitu: Pendidikan Nasional berfungsi mengembangkan kemampuan dan membentuk watak serta peradaban bangsa yang bermartabat dalam rangka mencerdaskan kehidupan bangsa, bertujuan untuk berkembangnya potensi peserta didik agar menjadi manusia yang beriman dan bertaqwa kepada Tuhan Yang Maha Esa, berakhlak mulia, sehat, berilmu, cakap, kreatif, mandiri, dan menjadi warga negara yang demokratis serta bertanggung jawab.

Bagi seorang guru hal yang paling membahagiakan dan menggembirakan adalah ketika melihat siswa - siswinya berhasil mendapat nilai yang memuaskan dalam prolehan nialai hasil belajarnya, oleh karena itu untuk mendapatkan hasil yang memuaskan itu tidak mudah bagi seorang guru untuk mengajarkannya kepada siswa - siswinya, agar mendpatkan nilai yang memuaskan tersebut, perlu ketekunan, keuletan dan teknik atau metode pembelajaran yang baik agar siswa-siswi terus semangat belajar dan kreatif di dalam kelas. Seiring dengan perkembangan zaman dan pemikiran manusia semakin maju, metode - metode dan strategi strategi baru terus di kembangkan, banyak bermunculan teori-teori baru yang di buat dengan tujuan mengaktifkan kegiatan belajar mengajar.

Guru harus memiliki kopentensi dalam mengajar agar dapat bertindak sebagai tenaga pengajar yang efektif, terlebih dahulu guru harus mengenal dan mengakui harkat dan potensi dari setiap individu atau siswa yang di ajarkannya, kemudian cakap dalam menyampaikan materi sehingga memudahkan siswa untuk mempelajari pelajaran yang 
diterimanya dibantu dengan mengembangkan dan mempergunakan metode-metode mengajar yang tepat sehingga terjadilah kombinasi - kombinasi dan variasinya yang efektif.

Seiring berkembangnya zaman dan pemikiran manusia semakin maju, metode-metode dan strategistrategi baru terus dikembangkan, banyak bermunculan teori - teori baru yang terus di kembangkan yang di buat dengan tujuan mengefektifkan kegiatan belajar mengajar yang saat ini sering disebut dengan pembelajaran kooperatif (cooperatife learning).

Robert E. Slavin mengatakan: Salah satu model pembelajaran yang bertujuan mengaktifkan kegiatan belajar mengajar siswa - siswi yang sering digunakan adalah pembelajaran kooperatif (cooperative Learning) Pembelajaran kooperatif merupakan strategi yang memfokuskan pada belajar tim agar siswa saling membantu satu sama yang lainnya dalam mempelajari materi - materi pembelajaran. Fungsi dari pembelajaran kooperatif adalah menambahkan kesadaran bahwa siswa perlu belajar untuk berfikir, mnyelsaikan masalah dan mengintegrasikan serta mengaplikasikan kemampuan dan pengetahuan mereka. Metode Student Teams Achiepment Division (STAD) ini merupakan salah satu metode pembelajaran kooperatif yang paling sederhana dan merupakan model yang paling baik untuk permulaan bagi guru yang baru menggunakan metode kooperatif.

Sebelum melakukan penellitian, peneliti melakukan observasi langsung ke lingkungan sekolah SD Negeri Kertamulya II dan melihat hasil belajar terutama di mata pelajaran Pendidikan Agama Islam, dari hasil pengamatan, ternyata siswa kelas V ini terdapat banyak permasalahan dalam pendidikan misalnya : rendahnya hasil belajar sisw di bidang pelajaran Pendidikan Agama Islam, hal ini dapat di lihat dari hasil nilai-nilai ulangan harian siswa-siswinya nialinya masih di bawah KKM, selain itu masih banyak juga permasalahan yang lain diantaranya motivasi siswa belajar, interaksi siswa tidak ada dikarenakan guru mendominasi, sehingga proses 
belajar mengajar masih monoton, kemauan untuk menghafal juga masih rendah. Dalam melakukan pendekatan kepada siswa-siswi dan guru mata pelajaran, peneliti melakukan wawancara supaya lebih mengetahuai seluk beluk dan problem apa saja yang di hadapai. Setelah melakukan wawancara peneliti bisa lebih memahami permaslahanpermaslahan yang ada, setelah mendapatkan data yang diperoleh dilapangan kemudian peneliti berusaha untuk mencari jalan keluar. Dan berdasarkan permasalahan di atas siswa - siswi perlu diberikan suatu strategi pembelajaran yang dapat meningkatkan keaktifan siswa dalam proses belajar mengajar. Oleh karena itu Metode pembelajaran kooperatif STAD ini menjadi solusi yang tepat untuk mengatasi maslah yang ada di SD Negeri Kertamulya II ini.

\section{METODE PENELITIAN}

Subjek penelitian penerapan metode pembelajaran kooperatif tipe STAD yaitu siswa-siswi kelas V SDN Kertamulya II tahun pelajaran 2015/2016 yang terdiri dari siswa laki - laki 7 orang siswi perempuan 9 orang. Metode penelitian ini menggunakan metode penelitian tindakan yang di fokuskan pada situasi kelas, atau lazim dikenal Classroom action research. Penelitian ini dilaksanakan dengan menggunakan desain penelitian tindakan kelas yang terdiri atas beberapa siklus. Masing - masing siklus terdiri dari perencanaan (planning) pelaksanaan tindakan (acting), pengamatan (observing), dan refleksi (reflecting). Instrumen dalam penelitian ini menggunakan lembar soal, LKS, lembar catatan lapangan dan wawancara.

\section{HASIL PENELITIAN DAN PEMBAHASAN}


Tabel 1

Hasil Belajar Siswa siklus I

\begin{tabular}{|c|c|c|c|c|}
\hline \multicolumn{3}{|c|}{ "NOMOR } & \multicolumn{2}{|c|}{ SIKLUS I } \\
\hline URUT & INDUK & NPSN & PRETEST & POSTEST \\
\hline 1 & 10111.001 & 0057625974 & 40 & 79 \\
\hline 2 & 10111.003 & 0053461174 & 40 & 55 \\
\hline 3 & 10111.017 & 0057984004 & 40 & 70 \\
\hline 4 & 1112.1 .002 & 0048934272 & 30 & 66 \\
\hline 5 & 1112.1 .004 & 0051568777 & 40 & 73 \\
\hline 6 & 1213.2 .023 & 0054575991 & 47 & 80 \\
\hline 7 & 1112.1 .006 & 0058187228 & 47 & 60 \\
\hline 8 & 1112.1 .011 & 0062388184 & 30 & 80 \\
\hline 9 & 1112.1 .014 & 0056451779 & 30 & 74 \\
\hline 10 & 1112.1 .015 & 0049755533 & 40 & 60 \\
\hline 11 & 1112.1 .016 & 0046656196 & 47 & 80 \\
\hline 12 & 1112.1 .017 & 0042907452 & 30 & 70 \\
\hline 13 & 1112.1 .018 & 0059786810 & 30 & 65 \\
\hline 14 & 1112.1 .021 & 0067953936 & 45 & 70 \\
\hline 15 & 1112.1 .022 & 0042968735 & 44 & 90 \\
\hline 16 & 1112.2 .024 & 0046135145 & 30 & 58 \\
\hline \multicolumn{3}{|c|}{ Jumlah } & 610 & 1130 \\
\hline \multicolumn{3}{|c|}{ Rata - rata } & 38,12 & 70,62 \\
\hline \multicolumn{3}{|c|}{ \% Pencapaian nilai KKM } & \multicolumn{2}{|c|}{$\frac{5}{16} \times 100=31,25 \%$} \\
\hline
\end{tabular}

Dari table di atas ini dapat diperoleh hasil pretest dan posttest pada siklus I, yang diperoleh bahwa rata - rata hasil pretest 38,12 dengan nilai terendah 30 dan teratas 47 dan posttest rata - rata 70,62 dengan nilai terendah 55 dan nilai teratas 90. Dari data ini dapat diketahui masih banyak siswa yang belum mencapai ketuntasan belajar atau KKM yang telah di tentukan oleh sekolah.

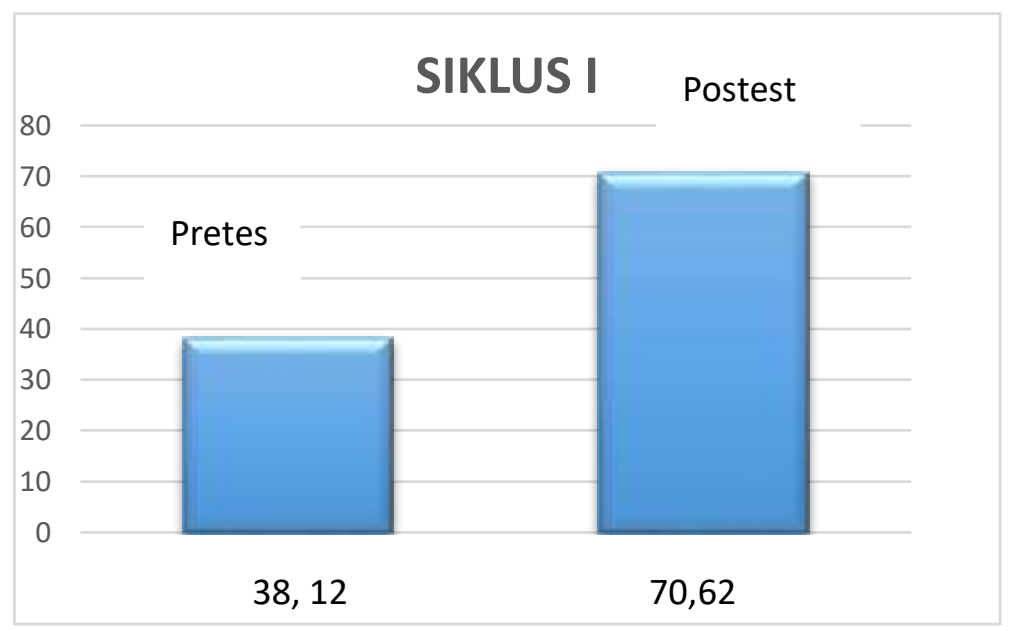

Gambar 1

Hasil Pemantauan pretest dan postest 
Pada Metode Cooverative Learning tipe STAD

Tabel II

Hasil Belajar Siswa siklus II

\begin{tabular}{|c|c|c|c|c|}
\hline \multicolumn{3}{|c|}{ NOMOR } & \multicolumn{2}{|c|}{ SIKLUS I } \\
\hline URUT & INDUK & NPSN & PRETEST & POSTEST \\
\hline 1 & 10111.001 & 0057625974 & 75 & 80 \\
\hline 2 & 10111.003 & 0053461174 & 80 & 80 \\
\hline 3 & 10111.017 & 0057984004 & 40 & 85 \\
\hline 4 & 1112.1 .002 & 0048934272 & 40 & 90 \\
\hline 5 & 1112.1 .004 & 0051568777 & 80 & 90 \\
\hline 6 & 1213.2 .023 & 0054575991 & 76 & 80 \\
\hline 7 & 1112.1 .006 & 0058187228 & 75 & 70 \\
\hline 8 & 1112.1 .011 & 0062388184 & 75 & 80 \\
\hline 9 & 1112.1 .014 & 0056451779 & 80 & 73 \\
\hline 10 & 1112.1 .015 & 0049755533 & 60 & 85 \\
\hline 11 & 1112.1 .016 & 0046656196 & 75 & 78 \\
\hline 12 & 1112.1 .017 & 0042907452 & 70 & 77 \\
\hline 13 & 1112.1 .018 & 0059786810 & 70 & 90 \\
\hline 14 & 1112.1 .021 & 0067953936 & 45 & 90 \\
\hline 15 & 1112.1.022 & 0042968735 & 85 & 80 \\
\hline 16 & 1112.2.024 & 0046135145 & 80 & 82 \\
\hline \multicolumn{3}{|c|}{ Jumlah } & 1106 & 1310 \\
\hline \multicolumn{3}{|c|}{ Rata - rata } & 69,12 & 81,87 \\
\hline \multicolumn{3}{|c|}{ \% Pencapaian nilai KKM } & \multicolumn{2}{|c|}{$14 / 16 \times 100=87,5$} \\
\hline
\end{tabular}

Dari table di atas ini dapat di peroleh hasil pretest dan postest dari siklus II, Maka data yang diperoleh bahwa rata - rata hasil pretest 69,12 dengan nilai terendah 40 dan teratas 80 dan postest rata - rata 81,87 dengan nilai terendah 70 dan nilai teratas 90. Dari data ini bisa dikatakan bahwa pada siklus II terjadi peningkatan hasil belajar siswa siswinya di bandingkan siklus I, yang dilihat dari hasil pretest dan postest, siswa - siswinya yang mendapat nialai diatas 75 ada 14 orang mencapai 87,5\%. Maka hasil yang di capai sudah baik yang ditandai dengan adanya peningkatan dari hasil nilai pretest dan postest dari siswa - 
siswinya yang melebihi KKM yang ditetapkan oleh sekolah yaitu 75 dengan ketuntasan $87,5 \%$, oleh
Karena itu peniliti cukupkan penelitian ini sampai siklus II.

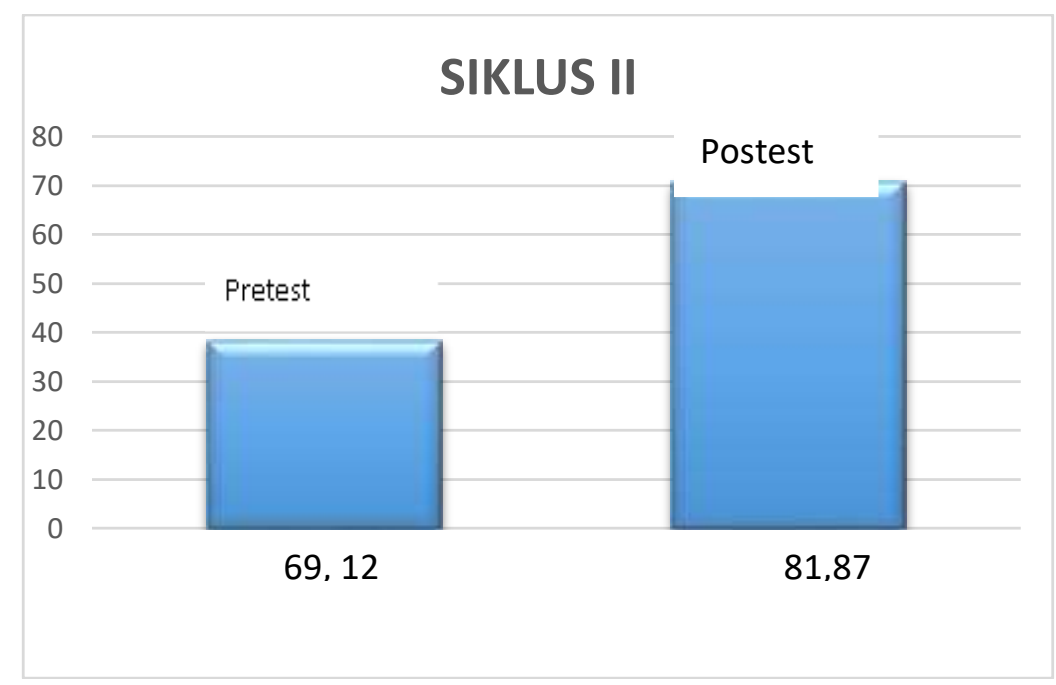

Gambar 2

Hasil Pemantauan pretest dan postest

Pada Metode Cooverative Learning tipe STAD
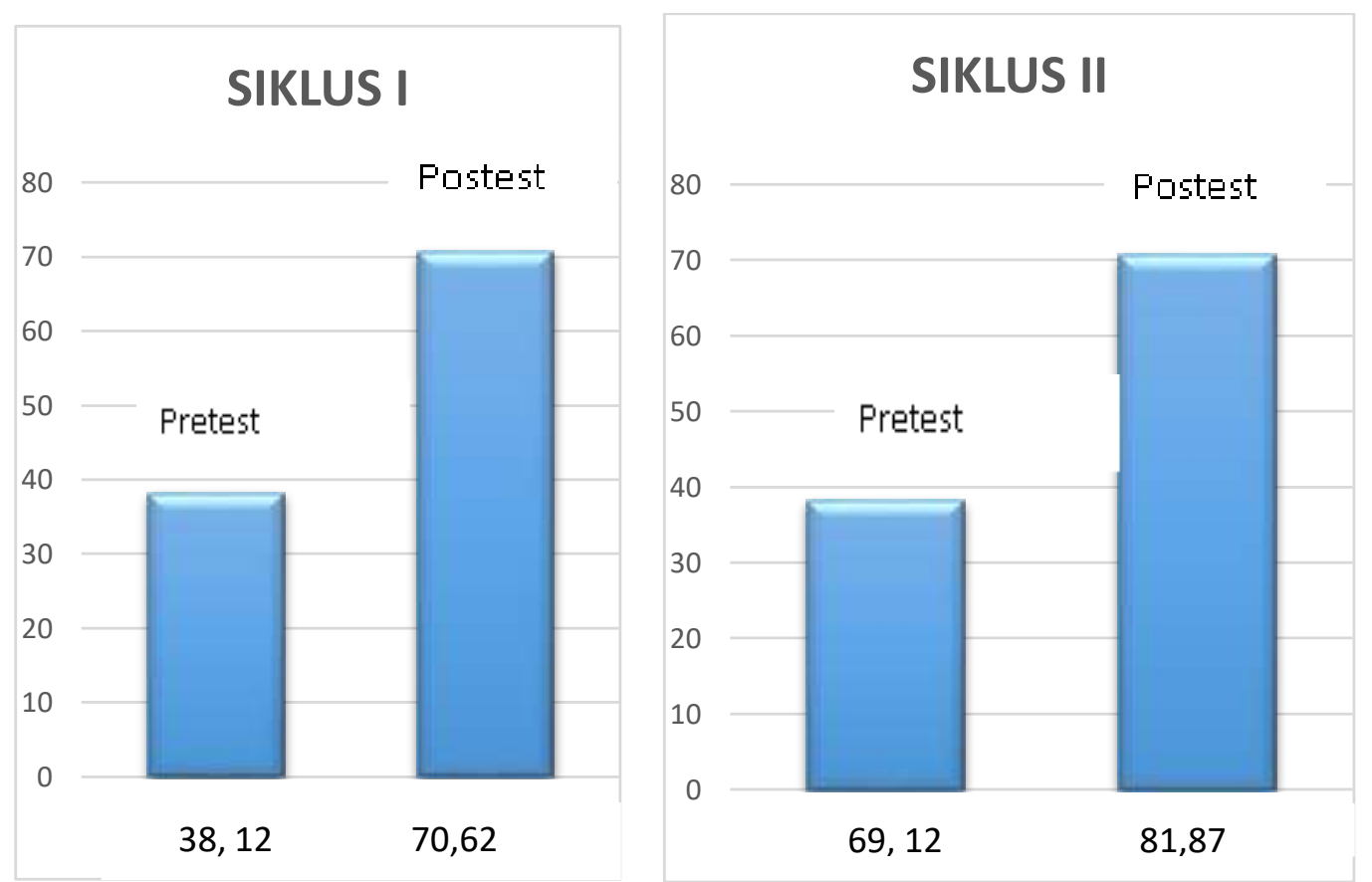

Gambar 3

Hasil Pemantauan pretest dan posttest gabungan dari siklus I dan II 


\section{PENUTUP}

Pada Metode Cooverative Learning tipe STAD

Berdasarkan hasil penelitian yang diperoleh, maka dapat ditarik kesimpulan bahwa terdapat peningkatan hasil belajar siswa-siswi yang diajarkan melalui pembelajaran Kooperatif tipe Student Teams Achievement Divisions (STAD) pada materi Pendidikan Agama Islam terbukti pada pelaksanaan sklus II $81,87 \%$ hasil tes akhir.

Pada pelaksanaan siklus I, data yang diperoleh siswa - siswinya rata rata hasil pretest $38,12 \%$ dengan nilai terendah 30 dan teratas 47 dan postest rata - rata 70,62 \% dengan nilai terendah 55 dan nialai teratas 90 . Pada siklus II, data yang diperoleh dari siswa - siswi rata-rata hasil pretest 69,12\%dengan nilai terendah 40 dan teratas 80 dan postest rata - rata $81,87 \%$ dengan nilai terendah 70 dan nilai teratas 90. Dari data ini bisa dikatakan bahwa pada siklus II terjadi peningkatan hasil belajar siswa dibanding siklus I, yang di lihat dari hasil pretest dan posttest, sisiwa yang mendapat nialai diatas 75 ada 14 orang mencapai $87,5 \%$, hasil yang di capai sudah baik yang ditandai dengan adanya peningkatan dari hasil nilai pretest dan postest siswasiswinya yang melebihi KKM yang ditetapkan oleh sekolah yaitu 75 dengan ketuntasan 87,5 \%, oleh karena itu peniliti cukupkan sampai siklus II.

\section{DAFTAR PUSTAKA}

Ali, Muhammad Daud. Pendidikn agama Islam, Jakarat: PT Raja Garafindo Persada

Frida, Maryat Yusuf. (2010) Penerapan Model Pembelajaran Kooperatiftipe STAD pada mata pelajaran Biologi untuk meningkatkan hasil belajar siswa SLTP Negri 2 Kota Gorontalo. Skripsi UNG: Tidak diterbitkan

Isjoni. (2009). Cooperative Learning. Bandung: Alfabet

Arikunto, Suharsimi. (2007). DasarDasar Evaluasi Pendidikan. Jakarta: Bumi Aksara

Syaiful, Bahri Djamarah dan Aswan Zain. (2006). Strategi Belajar Mengajar. Jakarta: Rineka Cipta. 
